\title{
The research on teaching reformation of photoelectric information science and engineering specialty experiments
}

Zheng Zhu, Fan Yang, Yang Zhang, Tao Geng, Yuxiang Li

Zheng Zhu, Fan Yang, Yang Zhang, Tao Geng, Yuxiang Li, "The research on teaching reformation of photoelectric information science and engineering specialty experiments," Proc. SPIE 10452, 14th Conference on Education and Training in Optics and Photonics: ETOP 2017, 104525T (16 August 2017); doi: $10.1117 / 12.2269883$

SPIE Event: 14th Conference on Education and Training in Optics and Photonics, ETOP 2017, 2017, Hangzhou, China 


\title{
The research on teaching reformation of photoelectric information science and engineering specialty experiments
}

\author{
Zheng Zhu ${ }^{\mathrm{a}}$, Fan Yang* ${ }^{\mathrm{b}}$, Yang Zhang ${ }^{\mathrm{a}}$, Tao Geng ${ }^{\mathrm{a}}$, Yuxiang $\mathrm{Li}^{\mathrm{a}}$ \\ ${ }^{a}$ Key Laboratory of integrated fiber optics, Ministry of education, National teaching center of \\ physical experiment, Harbin Engineering University, Harbin, China; \\ ${ }^{\mathrm{b}}$ School of Foreign Languages, Harbin University, Harbin 150001, China.
}

\begin{abstract}
This paper introduced the idea of teaching reformation of photoelectric information science and engineering specialty experiments. The teaching reformation of specialty experiments was analyzed from many aspects, such as construction of specialized laboratory, experimental methods, experiment content, experiment assessing mechanism, and so on. The teaching of specialty experiments was composed of four levels experiments: basic experiments, comprehensive and designing experiments, innovative research experiments and engineering experiments which are aiming at enterprise production. Scientific research achievements and advanced technology on photoelectric technology were brought into the teaching of specialty experiments, which will develop the students' scientific research ability and make them to be the talent suitable for photoelectric industry.
\end{abstract}

Keywords: Times Roman, image area, acronyms, references

\section{INTRODUCTION}

With the high-speed development of our country, social needs for high-tech applied talents are greater and greater. Photoelectric information science and engineering is a specialty linked and connected by many subjects, such as optics, photoelectronics, micro-electronics, communication, computer science, and so on. It involves the radiation, transmission and detection of optical information, the transformation, storage, disposal and display of optoelectronic information, etc., combining with undergraduate education to enhance students' practical ability with the purpose of cultivating innovative talents. As a new major field of our university, photoelectric information science and engineering has the characteristics of fast update of specialized knowledge, high demand of theoretical basis and wide range of practical application, and thus has a profound influence on the development of advanced technology of the society. Therefore, cultivating applied talents who have not only theoretical basic but also master the practical skills is the urgent need for social development. This specialty cultivates advanced professional talents who conform to the contemporary objective of personnel cultivation, master basic theories and methods, have better experimental ability and computer application ability, and are able to work on scientific research, scientific and technological development and teaching in physics and scientific and technological domains related to photoelectronics. Recent years, we have made up teaching syllabus in terms of training objective, set up photoelectron laboratory and given consideration to the course selection of similar specialties. During the teaching process of photoelectric information science and engineering, the teaching of specialty experiments plays a distinctive role in cultivation and training of students' practical ability, research ability and innovation ability which cannot be replaced with any other teaching link. The teaching aims of specialty experiments of photoelectric information science and engineering are to make the students grasp the basic theories of electronic techniques and optics; to learn the applications of optical principles, photoelectric detecting techniques and detecting instruments in practical production and scientific researches; and to let students further learn and master the knowledge in light source, photoelectric detectors and sensors. Through specialty experiment teaching, we can broaden the scope of knowledge of students majored in photoelectric information science and engineering, add perceptual knowledge of students, and cultivate students' abilities in investigating, analyzing and solving problems in practical engineering to lay a solid foundation for their future career.

Directing at the features of the courses of optoelectronic technique, i.e. large quantity of contents and sound theoretical basis, and weak foundation of students in our university, we adopt the teaching method of transferring class contents, grasping the leading edge of science and optimizing class contents, as well as the explanation of consequences and

14th Conference on Education and Training in Optics and Photonics: ETOP 2017, edited by Xu Liu,

Xi-Cheng Zhang, Proc. of SPIE Vol. 10452, 104525T - ( 2017 ICO, IEEE, OSA, SPIE

CCC code: $0277-786 \mathrm{X} / 17 / \$ 18 \cdot$ doi: $10.1117 / 12.2269883$ 
practical applications. Focus on the explanation of contents of practical applications of optoelectronic technique, maintain the echo of experiments and theoretical knowledge, and give play to the practical effects of course teaching to twice as much can be accomplished with half the effort. Therefore, experimental curriculum plays a vital role in the whole process of teaching optoelectronic technique. According to current situation of practical teaching in the universities, corresponding reform should be taken into consideration to improve the entire experimental teaching effects: integrating actual situation of the university, formulate and perfect operational practical teaching syllabus; reserve the operational experimental teaching forms that have been tested by practices to make a increasingly perfect system which can be popularized and utilized; during the process of experimental teaching, enhance the management and supervision of the process to make it not become a mere formality and thus gain a favorable effects.

This thesis aims at the specialty experiment teaching of photoelectric information science and engineering, and analyzes it from the construction of specialized laboratory, the experimental methods, the experiment content, experiment assessment mechanism, and so on.

\section{THE CONSTRUCTION OF SPECIALIZED LABORATORY}

During the process of teaching, the experimental teaching attachments provide a basic guarantee for the experimental teaching. However, during the process of current experimental teaching of photoelectronics, experimental teaching usually can not be done smoothly resulted from the problems of experimental teaching attachments. Optoelectronic technique experiments need a laser as the light source and precise instruments like spectrometer, photo detector, electrooptic display, etc. as the follow-up supports. The common character of these instruments is expensive and easy to damage. The components of the instruments are always damaged by students' carelessness, and they can not be replaced on time due to the limited experimental expenditure, which is a hinder to the experiments and thus influences the effective development of optoelectronic technique courses. In addition, the changing development of optoelectronic industry leads to the fact that experimental equipment can not keep up with the course contents, which forces the experiment teachers only to provide comparatively backward experimental projects for the students and thus is contradicting to the teaching objective of cultivating applied talents vigorously during the transformation development of the university.

Therefore, the results of experimental teaching, to some extent, depend on the experimental teaching facilities. In order to improve the experimental teaching effect, more funds should be put into to reinforce the infrastructure construction of the laboratories. Experimental facility is the basic condition of experimental teaching and its significance is self-evident. Deploy the current limited experimental facilities reasonably of the university as the basic guarantee of experimental teaching of optoelectronic technique. Therefore, we have to integrate the existing condition of other labs with that of photoelectronic information complex laboratory; based on experimental facility plan, set up the basic parameters and measurement accuracy of the experimental facility according to service condition; design the structures of new instruments and equipment; improve some structures according to actual use; and purchase experiment materials reasonably to strive for the chances and platforms for every student, aiming at cultivating students' basic professional skills and improve their engineering practice ability. There is no doubt that cultivating students' active exploration competence in the laboratories with excellent facilities can greatly stimulate students' learning initiatives, and better cultivate their operational abilities; therefore, the infrastructure construction of the labs is crucial to experimental teaching. As for the construction of the laboratories, on one hand, apply for the funds of laboratory construction based on discipline basis, i.e. boost laboratory construction step by step through project funding; on the other hand, seek cooperation with coherent units to achieve win-win through project cooperation, i.e. train students' experimental ability as well as promoting laboratory construction.

\section{IMPROVING EXPERIMENTAL TEACHING METHODS}

In traditional specialty experiment teaching of photoelectric information science and engineering, the teaching method is mainly adopted that the teacher explains and demonstrates the experiment and the students imitate and practice it. Although this method is combined with doing experiments themselves, its nature still inclines to explain and pass on knowledge, which cannot stimulate students' learning interests and go against the cultivation of innovation consciousness. Therefore, more effective experimental teaching method has to be explored based on traditional experimental teaching method to enhance the quality of experimental teaching. Arouse students' interests in exploring the unknown world with original experimental contents. For instance, when teaching the nonlinear optical frequency transformation technique, raise the question: Can a ray of invisible laser generate various kinds of visible lights under 
certain condition, which can arouse students' interests to continue to focus. Then through teacher's experiment demonstration, invisible laser can be converted into various colors of light like red, orange, yellow, green, etc. under different experiment conditions. With this guidance of intense interest, students can't help exploring the experiments and understanding experiment principles. Therefore, fine experiment contents and innovative experiment methods can twice the result with half the effort.

At present, multimedia courseware is one of the teaching methods in the universities. It can arouse students' interests more vividly and directly, stimulate their creative thinking, open up their thinking, broaden their horizons, and thus deepen their understanding of optoelectronic technique. Students can have a visual cognition for some component or device by playing courseware in class, which can enrich teaching contents, make students understand learned knowledge easily, and thus overcome the tediousness of traditional teaching method and arouse students' interests. In addition, directing at the characteristics of specialty experiments of photoelectric information science and engineering, the teaching of specialty experiments can be realized by combining project teaching method based on experiment facilities with online teaching method based on network resources and virtual simulation technology. By utilizing network resources and virtual simulation technology, students can learn the experiment contents before class, grasp part of them, and propose some questions; they can learn more effectively directing at their questions when doing experiments in class, and thus get deeper understanding of the key contents of experimental teaching.

Aiming at the lack of preparations before class, request strictly both teachers and students. Experiment teacher must have deep understanding of experiment principles and be familiar with experiment facilities. On this basis, require strictly that students do full preparations before class, and postpone the experiments of those who have not previewed the experiments to supervise and urge them to finish their jobs. Not until both teachers and students have full preparations, could they have a definite object in view during the experiments and thus have innovations. Since the preparations have been made, based on the fact that both teachers and students hope to be acknowledged, the subjunctive initiatives of students can really be aroused, the leading role of teachers can inevitably replaced with students, and thus the transformation of educational pattern from tradition to modern can be realized. And students can do productive thinking with teachers' guidance to make the experiments creative.

Experiment teachers are employed and managed by experiment center. They take on the teaching task of optoelectronic experiments and are scheduled by experiment center, which is not only beneficial for the management of full-time teachers of experiments, but also creates beneficial condition for the construction of experiment teaching staff. As for resources, all the experimental apparatus and equipment of optoelectronic experiment center are under unified management with specially-assigned person to guarantee the serviceability rate of experimental facilities.

\section{TEACHING EXPERIMENT CONTENTS BY DIFFERENT LEVELS}

The specialty of photoelectric information science and engineering has the characters of wide coverage and plenty of knowledge points. Different experiments have different difficulties, and their levels of difficulty are quite large. Therefore, directing at the experimental teaching of photoelectric information science and engineering, conduct the experimental teaching by different levels of difficulty, which conform to the learning psychology of undergraduates. At basic teaching level of optoelectronic experiment, students can read the teaching materials, references and document literature of photoelectric technique experiment corresponding to university level on their own; at high teaching level, students can independently operate or design related photoelectric experiments and productions. On this basis, cultivate students' abilities of using various kinds of manuals of photoelectric techniques and looking up and selecting related devices and combinations of experiment contents independently to make them reflect on problems of cross-optics and its subdisciplins, electronics and computer science gradually, and thus cultivate their capacity for scientific research.

Let students learn gradually from deeper understanding knowledge points and understanding and applying to specialized knowledge to gaining the ability to find, analyze and solve problems; thereby, improve their operational ability and innovative consciousness, cultivate high-quality talents possessing practical application ability for the society, and thus achieve the goal of serving the society and finally realize the combination with social enterprises, and cultivate students to become professionals built for photoelectric enterprises. In terms of the development trend of experimental teaching and the actual situation of our university, the experimental teaching can be divided into four levels: 


\subsection{Basic experiments}

According to the knowledge structure and inherent laws of photoelectronics, with the principal lines of the generation, transmission, exchange, and detection of light, optical elements and electro-optical signal processing, and the leading of the latest development of energy of photoelectron and optoelectronic information, combine experiment courses with theoretical courses to form integrated modularized curriculum system of specialty experiments of photoelectronics. Experimental teaching is a significant link of advanced engineering colleges cultivating high-quality talents; Experimental teaching, facing senior college students, has the characteristics of large quantity of contents and sound comprehensiveness and specialty, which plays a unique role that can not be replaced with other teaching links in training students' practical ability, research ability and innovation ability.

Specialty basic experiments are the experiments aiming at deeply understanding the basic concepts of optics and photoelectronics and enhancing the perceptual intuition of basic optical phenomena and rules, with the purposes of understanding the experiment techniques and analytical method of optics and photoelectronics to combine the theoretical knowledge with experiments and thus to enhance the teaching effects. The combination of theory and experiments can make students not only do experiments with learned knowledge to enhance their operational ability, but also gain deeper understanding of theoretical knowledge by observing experiment phenomena and thus deepen their understanding of the basic principles. Specialty basic experiments place extra emphasis on deeper understanding of key knowledge points and basic training of engineering practices, whose key point is to train students' ability to operate and use basic equipment and tools. Let students understand and grasp the basic principles and concepts of optics and photoelectronics; the principles and usage of various basic instruments of photoelectronics; the operating principles, manufacturing process, index parameters and test method of photoelectronic components and parts in common use. On this basis, let them understand grasp preliminarily the design and test method of optical and photoelectronic system. Make students become regular professional talents of photoelectric information science and engineering via experimental teaching.

\subsection{Comprehensive and designing experiments}

In education of talented persons, it is crucial to cultivate students' learning interests. Interest plays an important role as the internal motivation in the process of learning and cognition. Therefore, try every means to stimulate their learning interests in experimental teaching. When designing and producing experimental facility, moderately increase the interestingness of experiment project and let students actively participate in the whole process of experiments to feel the joy learning and the pleasure of success.

Comprehensive and designing experiments mainly aim at senior students in photoelectronics, which play a vital role in the whole experimental teaching of photoelectronics. They involve massive physical knowledge with integrity and technology. With the premise that students have grasped some basic professional knowledge of photoelectric technology, fiber optical communication technology, laser properties and principles, this level of experiments can fully exert students' subjective initiative, i.e. let them design experimental scheme on their own, to deepen their understanding and application of professional knowledge, enhance the cultivation of their operational ability and learn to grasp the new concepts in photoelectronics by coordinating experimental methods and skills with theoretical courses. Provide the platform of self presentation with students by participating in the design of experiments, sufficiently stimulate their subjective initiatives, and cultivate their innovation ability. Students can actively explore the unknown domains with the guidance of experiment teachers, which consolidate their theoretical knowledge as well as their practical operational ability. Comprehensive and designing experiments can train students from various angles, levels and ways and raise questions to them to train their ability of analyzing problems and solving problems; meanwhile, it is an important means to cultivate students' practical ability and innovation capacity. It can enhance their understanding and application of professional knowledge and help them learn to grasp the new concepts of the major domains of photoelectronics by combining experimental methods and skills with theoretical courses. Increasing comprehensive and designing experiments is the key to the reform of experiment contents. However, increasing comprehensive and designing experiments does not mean simply replacing verification experiments with comprehensive and designing experiments, but considering students' gradual-rising comprehensive design capacities.

During this process, the teacher changes his role from the primary instructor to a supervisor, director, assistant, etc. The supervisor refers that when the students do the experiment, the teacher must supervise the whole process from the experiment principle and project design to the check of materials; otherwise, some of the students may be perfunctory and the anticipative experiment teaching aims can not be achieved. The director refers that when the students don't do the experiment smoothly, the teacher must give some guidance, especially at the phase of principle and project design. 
The assistant refers that when the students do the experiment, the teacher should supply them with the conditions like looking up literature, preparing the instruments, etc. and have discussions with them. Emphasize students' autonomy, pay attention to the enlightening and comprehensiveness of the experiments, and cultivate their ability and attainment to solve practical problems with optical knowledge.

\subsection{Innovative research experiments}

Based on the correlation and complementary of specialty experimental teaching and scientific research, transforming the content of scientific research task into the experimental project of specialty experimental teaching can gain better effects of specialty experimental teaching and also solve the problems of equipment and expenditure of specialty experimental teaching. In addition, the transformation of scientific research achievements into operable experiment contents can also enrich the experiment contents of basic, comprehensive and designing experiments. With the guidance of the idea of scientific research leading experiment teaching, the teachers propose the scientific research achievement that can possibly be transformed into experimental teaching, and the transformation should be planned and implemented by both teachers and students. On the other hand, let students who have potentials and interests in experiments explore independently, ask questions by themselves, put forward the solutions under existing condition, and implement them with teachers' guidance. This kind of experiments lays emphasis on cultivating students' ability of raising and solving problems and enhancing experiment explorations, with an eye to the cultivation of students' innovation and independent working ability.

Furthermore, with the development of research innovation experiments, students can have sufficient freedom of choice, which can give play to their potentials more sufficiently, especially for those who want to continue postgraduate study and those who work on technology-based career, which plays a positive role in their thinking and way to solve problems in their future work.

\subsection{Engineering experiments of business-oriented production}

The cultivation of professionals must satisfy social needs. The photoelectronic industry of our country is at the phase of fast development, which means a large number of professionals with photoelectronic techniques are needed. From the perspective of talent cultivation of higher education, the main problem is that the major setting and cultivation direction are not geared to the needs of enterprises. According to the new "demand-oriented" pattern of talent cultivation, establish engineering experiments faced enterprises of large-scale instruments and equipment to satisfy their needs of professional skills. Therefore, the close cooperation and exchange with related enterprises is an effective means to connecting professional cultivation with social needs. In practical teaching, it is crucial to cooperate with the industry, strive for the cooperation with photoelectronic enterprises, organize students to visit and interview the enterprises and take part in engineering training to make them know the development of photoelectronic industry, which can promote their transformation and expansion of theoretical course knowledge and enhance their ability to solve practical problems.

According to the practical needs of production and the leading edge of research and development, improve students' practical operational ability and the ability of research and development of products via practical training. Let students understand the basic concepts in optics and photoelectronics, and grasp the basic principles, measuring and testing techniques and analytical method of optics and photoelectronics. Focus on deepening their understanding of basic concepts of optics and photoelectronics and broadening their scope of knowledge.

\section{EXPERIMENT ASSESSMENT MECHANISM}

Experiment teaching assessment mechanism is an indispensable part of specialized experiment teaching of photoelectric information science and engineering. In traditional experiment teaching assessment, teachers check and evaluate students, emphasizing checking and evaluating the acquisition of knowledge, which is not beneficial to the check of students' practical ability. Traditional question types and pattern of exam are only fit for the evaluation of students' theoretical knowledge, and the exam results present artificial unfairness due to the differences of content deviation and thus influence students' learning initiatives. However, experimental ability is a comprehensive ability to apply theoretical knowledge to practices, and traditional question types and pattern are not qualified to the assessment task; thereby, new pattern should be explored for the assessment of experimental teaching.

Therefore, the transformation must be made from monistic summative evaluation to formative evaluation. Not only assess students' experiment achievements, but also pay attention to the assessment of their experimental process, 
especially their abilities represented during the process of project experiments, such as ability of looking up data, experiment design ability, cooperation and exchange ability, innovation ability, etc. to enhance their comprehensive quality.

In this pattern, the teacher-student relation, compared with traditional classroom teaching, is more open, interactions between teachers and students are more frequent, the ways of interactions are more diverse, the contents are more, and the contacts between teachers and students are more multiple. In this kind of open environment, student thinking can become more active when students facing different teachers, there are more collisions and blending of different thoughts, teachers can be more satisfied with sense of teaching achievements, and students' learning enthusiasm can be greatly stimulated and encouraged.

\section{CONCLUSION}

This paper aims at the characteristics of specialty experimental teaching of photoelectric information science and engineering; analyzes construction of specialty laboratory, experimental methods, experiment content, and experiment assessing mechanism for the teaching reformation; puts forward four levels of specialty experiments, i.e. basic experiments, comprehensive and designing experiments, innovative research experiments and engineering experiments; and introduces scientific research achievements and advanced technology on photoelectric technology to the teaching of specialty experiments to develop the students' scientific research ability and make them to be the professionals suitable for photoelectric industry.

\section{REFERENCES}

[1] Niu, J., Yang, Q., Cong, Y., Liu, D., Cao, B. and Zheng, J., "Construction and innovation of experimental teaching center of optoelectronics to meet demand of market," Experimental Technology and Management 28(7), 268-273(2011).

[2] Yang, C., Liu, J. and Wang, Y., "Practice and exploration of constructing experimental teaching center of optoelectronics," Experiment Science and Technology 6(4), 165-167(2008).

[3] Ge, J., "Intensify practice education - the exploration of teaching reform in course of optoelectronics," Optical Technique 35(suppl.), 167-170 (2009).

[4] Hu, J., Xu, J., Dong, X., Zhao, J. and Zhang, Z., "The idea and practice about building photo-electronics labs," Research and Exploration in Laboratory 25(10), 1306-1308(2006).

[5] Li, L. and Liu, H., "The teaching reform and construction of practice in optoelectronics," Journal of Educational Institute of Jilin Province 30(3), 49-50(2014).

[6] Wang, Y., Luo, Q., Liu, J. and Cao, D., "The exploration of the continuable development of the practical teaching through setting the responsible professors," Chinese Journal of Scientific Instrument 31(8), 205209(2010).

[7] Liu, H., Wang, J. and Li, J., "Optoelectronic technology experimental teaching reform," Valuable Project 13(suppl.), 256(2012).

[8] Li, D. "The exploration of experimental teaching reform in optoelectronics," Science and Technology Information 15, 168(2010). 